\title{
Bone density and body composition in newly licenced professional jockeys
}

\author{
K. A. Jackson ${ }^{1}$ - M. T. Sanchez-Santos ${ }^{1,2}$ - A. L. MacKinnon ${ }^{1}$ • A. Turner ${ }^{1}$ • \\ K. Kuznik ${ }^{1,3}$ • S. Ellis ${ }^{1}$ • C. Box ${ }^{4}$ - J. Hill ${ }^{3}$ • M. K. Javaid ${ }^{1,5}$ - C. Cooper ${ }^{2,5}$ • \\ N. K. Arden ${ }^{1,2,5} \cdot$ J. L. Newton ${ }^{1}$
}

Received: 17 October 2016 / Accepted: 8 May 2017 / Published online: 13 June 2017

(C) The Author(s) 2017. This article is an open access publication

\begin{abstract}
Summary The primary objective is the description of bone mineral density (BMD) and body composition in newly licensed jockeys. One in three male, flat jockeys has a very low bone mineral density. Further research is needed to assess the short-term risk of fractures and long-term health implications of these findings.

Introduction Describe bone mineral density (BMD) and body composition in entry-level male and female, flat and jump jockeys in Great Britain.

WHAT THIS STUDY ADDS

- Large, representative cohort of male and female entry-level jockeys

- Twenty-nine percent of male, flat jockeys and $13 \%$ of male, jump jockeys have Z-scores $<-2.0$

- Significantly lower spine BMD in male flat jockeys than female jockeys

- Higher BF \% and lower LM in male flat jockeys compared to other weight-restricted sports
\end{abstract}

Electronic supplementary material The online version of this article (doi:10.1007/s00198-017-4086-0) contains supplementary material, which is available to authorized users.

\section{K. A. Jackson}

kate.jackson@ndorms.ox.ac.uk

1 Arthritis Research UK Centre for Sport, Exercise and Osteoarthritis, Nuffield Department of Orthopaedics, Rheumatology and Musculoskeletal Sciences, University of Oxford, Oxford, UK

2 Oxford NIHR Musculoskeletal Biomedical Research Unit, Nuffield Department of Orthopaedics, Rheumatology and Musculoskeletal Sciences, University of Oxford, Oxford, UK

3 British Horseracing Authority, 75 High Holborn, London, UK

4 University of Oxford Medical School, Oxford, UK

5 MRC Lifecourse Epidemiology Unit, Southampton General Hospital, University of Southampton, Southampton, UK
Methods Data was collected on jockeys applying for a professional jockey license between 2013 and 2015. Areal BMD at the spine, femoral neck (FN), total hip and body composition were assessed by dual-energy X-ray absorptiometry (DXA) scan. We examined differences between BMD and body composition by gender and race type (flat or jump). Volumetric bone mineral apparent density (BMAD) of the spine and FN was also calculated to account for group differences in bone size.

Results Seventy-nine male flat jockeys (age 18.5 \pm 1.9 , BMI $19.0 \pm 1.4$ ), 69 male jump (age $20.7 \pm 2.0$, BMI $20.6 \pm 1.3$ ) and 37 female flat jockeys (age $19.3 \pm 2.0$, BMI $20.8 \pm 1.7$ ) took part in this study. Spine BMD Z-scores $\leq-2$ for male flat, male jump and female flat jockeys were 29, 13 and $2.7 \%$, respectively. Spine BMD was lower in male than female flat jockeys $(p<0.001)$. All BMD scores were lower in male flat compared to male jump jockeys $(p<0.001)$. Body fat percent (BF \%) was lower in male flat jockeys compared to male jump and female flat jockeys $(p<0.05)$. Lean mass index (LMI) was lower in male flat compared to male jump jockeys $(p<0.001)$. Conclusions Male flat jockeys had a significantly lower BMD, LMI and BF\% compared to jump jockeys and female flat jockeys. Male flat jockeys had lower spine BMD scores than females. Individual bone maturation may influence these findings. Further investigation into the relevance of low BMD and altered body composition on jockey health is required.

Keywords Athlete $\cdot$ Body composition · Bone density · DEXA · Jockey

\section{Introduction}

Professional horse racing is a popular sport in the UK. It is divided into flat racing and jump (National Hunt) racing. Flat racing involves distances of 5-20 furlongs (1 furlong 
$=0.201 \mathrm{~km})$, whereas jump racing covers longer distances (16-36 furlongs) with horses jumping over a minimum of eight obstacles. In the UK, there are currently over 400 licenced professional jockeys, over 350 amateur jockeys and over 5000 stable staff.

Newly licenced jockeys are an important sub-group of jockeys to study. In this weight-restricted sport, unhealthy weight loss strategies are used by jockeys to make weight for a race, $[1,2]$. This may have negative effects on jockey health $[3,4]$. Less-experienced jockeys are under further pressure to make lower weights as a result of being able to carry a 'claim'. Currently, in the UK, flat jockeys have a minimum riding weight of 8 stone $(50.8 \mathrm{~kg})$. However, when first licenced, they can claim a weight allowance which allows them to race-ride $7 \mathrm{lbs}$ lighter, i.e. 7 stone $7 \mathrm{lbs}(47.6 \mathrm{~kg})$. This claim reduces as the jockey wins races and ceased altogether once they have 95 winners. Race riding at a lower weight than more experienced riders is felt to help compensate for their inexperience.

Newly licenced jockeys are young (between the ages of 16-25 years) and should have achieved $90 \%$ of peak bone mass by their early 20 's. Therefore, lifestyle choices in the newly licenced jockey population is key for their immediate, but also future, bone health [5].

Several small studies have identified low bone mineral density (BMD) in the male jockey population. Despite the limitations of small sample sizes and potential recruitment bias, these studies suggest a worrying trend [6-10]. Female jockeys seem to be at less risk of low BMD although current evidence for this is limited [11]. Low BMD is known to be associated with an increased risk of both traumatic and low-impact fractures in older populations [12]. There is an assumption that this would be the same in a younger population, but evidence for increased traumatic fracture risk with low BMD is lacking. Jockeys fall off their horses at speed and from a height on a relatively frequent basis and thus are at risk of traumatic injury. Jump jockeys fall more often but have less injuries per fall (UK data 68 falls per 1000 rides; 180 injuries per 1000 falls); whereas, flat jockeys fall less often, but are more likely to injure themselves (UK data 4.4 falls per 1000 rides; 398 injuries per 1000 falls) [13]. Bone fractures are one of the commonest injuries sustained [14].

The significance of body composition for injury and health in jockeys is not currently clear. Previous studies have observed lower body fat $[2,6,9,11]$ and lean mass in jockeys $[6,11]$ when compared to the normal population. Epidemiological studies have shown lean mass (LM) to have a significant positive correlation with BMD $[15,16]$. Fat mass (FM) appears to have weaker positive correlation to BMD, and this relationship is affected by age, gender and menopausal status [15]. If the weight-bearing effect of the FM is adjusted for, a higher FM may in fact have an inverse association with BMD [17]. Underlying muscle weakness has been postulated as a contributing factor to the high rates of falls and subsequent injury in racing [18].

Current literature suggests a significant problem with bone health in this population, and our aim is to examine bone health and body composition parameters in a larger, more representative cohort of male and female jockeys. The primary objective is to describe whole body BMD in newly licenced professional jockeys with sub-analysis by gender and race type. The secondary objective is to describe body composition in newly licenced professional jockeys with sub-analysis of the same factors.

\section{Methods}

\section{Subjects}

All entry-level professional jockeys attending the professional jockey licencing courses between January 2013 and November 2015 were invited to have a DEXA scan performed as part of their medical screening. There were 216 newly licenced jockeys reported by the PJA in this time frame. One hundred and eighty-six flat and jump jockeys (86\%) took part in the screening programme. The screening involved a routine DEXA scan performed at the time of initial licence. Data was collected by the medical department at the British Horse Racing Authority (BHA) and by the Professional Jockeys Association Medical Adviser (PJAMA). The data was anonymised before being exported for analysis by the study team.

\section{Ethics approval}

Ethics approval (MS-IDREC-CX-2014-147) was obtained for this study from the Central University Ethics Committee (CUREC).

\section{Assessment of bone and body composition}

Bone mineral content (BMC), bone area (BA) and areal BMD at the spine (L1-L4), femoral neck (FN) and total hip as well as body composition (FM and LM (excluding bone mass)) were assessed by DXA scan using two Hologic Discovery densitometers ( $n=146$ and $n=3$ images, respectively), and one mobile Hologic Explorer ( $n=37$ images).

The BMD $\left(\mathrm{g} / \mathrm{cm}^{2}\right)$ Z-score (number of standard deviations (SD) more or less than a same age group and sex reference mean) at the spine, FN or total hip of $\leq-1$ and $\leq-2$ was used to sub-group participants, [19, 20]. 'National Health and Nutrition Examination Survey (NHANES) 2008' reference database was used [21].

Areal BMD tends to underestimate true BMD in small, thin individuals. Therefore, the best way to eliminate the effect of bone size on BMD in this young population was to calculate the volumetric bone density, or bone mineral apparent 
(BMAD) $\left(\mathrm{g} / \mathrm{cm}^{3}\right)$ [22]. The BMAD values [22, 23] were calculated for the lumbar spine and FN as follows:

$$
\begin{aligned}
& \text { Spine BMAD }=\text { BMC of spine } / \text { area }^{3 / 2} \\
& \text { FN BMAD }=\text { BMC of FN/area }
\end{aligned}
$$

A comparison study on BMD measurements between the two Hologic Discovery scanners using a Europeanstandard phantom spine was performed. Ten phantom samples with the same characteristics were entered in each instrument software programme. Bland Altman plots and coefficient of variations $(\mathrm{CV})$ of the scanners were calculated, and they showed very good levels of agreement and good machine precision (CV\% <1.2\%). (Text A.1). The Explorer Hologic machine was dismantled, so we were not able to include it in the comparison study.

Height and body mass were measured following standardised procedures before the DEXA scan was performed. Body weight was measured with a set of Seca electronic weighing scales and body height was measured standing using a height measure. Body mass index (BMI) was calculated as the ratio of the weight to the square of height in meters $\left(\mathrm{kg} / \mathrm{m}^{2}\right)$. It was categorised according to the World Health Organization (WHO) classification: underweight $\left(\mathrm{BMI}<18.5 \mathrm{~kg} / \mathrm{m}^{2}\right)$, normal weight $(18.5$ $\leq \mathrm{BMI} \leq 24.9 \mathrm{~kg} / \mathrm{m}^{2}$ ) and overweight/obesity (BMI $\left.\geq 25 \mathrm{~kg} / \mathrm{m}^{2}\right)$ ), and was also used as a continuous variable in this analysis. The two suggested height-normalised indices for body composition, LM index (LMI) and FM index (FMI) was calculated as LM/height squared $(\mathrm{kg} /$ $\mathrm{m}^{2}$ ) and $\mathrm{FM} /$ height squared $\left(\mathrm{kg} / \mathrm{m}^{2}\right)$, respectively. Body fat percentage $(\mathrm{BF} \%)$ was assessed as FM $(\mathrm{kg})$ as a percentage of total body weight $(\mathrm{kg})$.

\section{Statistical analysis}

All analyses were conducted using the Stata version 13.1 statistical software (StataCorp, College Station, TX). The distribution of bone density and body composition were analysed by gender and race type (flat or jumps). There was only one female jump jockey who was therefore excluded from the analysis. Subject characteristics, bone measurements and body composition measurements were summarised by mean and SD or medians and percentiles for continuous variables and frequency (percentage) for categorical variables. Differences between groups (male flat jockeys vs. male jump/female flat jockeys) were identified using an independent samples $t$ test or Mann-Whitney $U$ test depending on data distribution and chi-squared if the variables were categorical.

To examine whether the different scanner may contribute to differences between groups, analyses were repeated excluding jockeys measured by the Hologic Explorer scan $(n=37)$. No substantial differences in the results were observed (Table A.2.1).

The level of significance was set at $p<0.05$ for all statistical analysis.

\section{Results}

\section{Descriptive data}

Descriptive data and anthropometric characteristics are presented in Table 1. Forty-two percent of the participants were male flat jockeys, $37.1 \%$ male jump jockeys and $19.9 \%$ were female flat jockeys. The mean \pm SD age of male jump jockeys (20.7 \pm 2.0 years old) and female flat jockeys $(19.3 \pm 2.0)$ was significantly higher than that of male flat jockeys (18.5 \pm 1.9$)$, $p<0.001$ and $p=0.03$, respectively. There were significant differences in weight and height between groups. Male flat jockeys were shorter and lighter than male jump jockeys, but they were taller and heavier than the female, flat jockeys (1.67 vs. $1.76 / 1.57 \mathrm{~m}$ and 52.9 vs. $63.7 / 51.6 \mathrm{~kg}$, respectively) (Table 1). Differences between the groups also reached significance for FM and LM. Male flat jockeys had a smaller LM

\begin{tabular}{|c|c|c|c|c|c|}
\hline & $\begin{array}{l}\text { Male } \\
\text { Flat }\end{array}$ & Jump & $\begin{array}{l}\text { Female } \\
\text { Flat }\end{array}$ & $\begin{array}{l}\text { Flat-male vs. } \\
\text { flat-female } \\
p \text { value }\end{array}$ & $\begin{array}{l}\text { Flat-male vs. } \\
\text { jumps-male } \\
p \text { value }\end{array}$ \\
\hline$N(\%)$ & $79(42.5)$ & $69(37.1)$ & 37 (19.9) & & \\
\hline Age (years) & $18.5 \pm 1.9$ & $20.7 \pm 2.0$ & $19.3 \pm 2.0$ & 0.03 & $<0.001$ \\
\hline Weight $(\mathrm{kg})$ & $52.9 \pm 2.9$ & $63.7 \pm 3.6$ & $51.6 \pm 4.0$ & 0.04 & $<0.001$ \\
\hline Height (m) & $1.67 \pm 0.06$ & $1.76 \pm 0.05$ & $1.57 \pm 0.05$ & $<0.001$ & $<0.001$ \\
\hline LM (kg) & $42.5 \pm 2.6$ & $50.7 \pm 3.1$ & $36.4 \pm 2.7$ & $<0.001$ & $<0.001$ \\
\hline FM (kg) & $7.6 \pm 1.3$ & $9.9 \pm 1.7$ & $12.4 \pm 2.4$ & $<0.001$ & $<0.001$ \\
\hline
\end{tabular}

Table 1 Jockey characteristics according to gender and type of racing

Values are mean \pm SD except where noted.

$L M$ lean mass, $F M$ fat mass 
and FM than the male jump group and smaller FM values than the female flat jockey group. In contrast, male flat jockeys had greater LM than that of the female flat jockeys.

\section{Bone mass}

All measurements of bone mass are shown in Table 2. The $\mathrm{BMC}$ and BMD at all skeletal sites were significantly lower in male flat jockeys than in male jump jockeys (Table 2). Male flat jockeys also had lower BMC at the spine than the female flat jockeys, but significantly higher BMC values at the FN and at total hip. Differences between BMD at the spine and at total hip were found in male and female flat jockeys, being significantly lower in male; however, no differences between $\mathrm{BMD}$ at $\mathrm{FN}$ were found.

Male flat jockeys had significantly lower bone density of the spine, FN and at the hip than male jump jockeys and female flat jockeys.

Both lumbar and FN BMAD values were significantly lower in male flat jockeys than in male jump jockeys and female flat jockeys, indicating that the actual density differences between groups are independent of differences in bone size.

\section{Body composition}

There were significant differences in body composition by gender and type of racing (Fig. 1). The mean $\mathrm{BMI} \pm \mathrm{SD}$ was $19.0 \pm 1.4,20.6 \pm 1.3$ and $20.8 \pm 1.7 \mathrm{~kg} / \mathrm{m}^{2}$ in male flat, male jump and female flat jockeys, respectively. Underweight was present in $39.2 \%$ of male flat, $4.4 \%$ of male jump and $10.8 \%$ of female flat jockeys. No jockeys presented overweight/ obese. LMI, FMI and BF\% were significantly lower in male flat jockeys compared with male jump jockeys (LMI $15.3 \pm 1.1$ vs. $16.4 \pm 1.1 \mathrm{~kg} / \mathrm{m}^{2}$; FMI $2.7 \pm 0.5$ vs. $3.2 \pm 0.6 \mathrm{~kg} / \mathrm{m}^{2}$ and BF\% $14.6 \pm 2.3$ vs. $\left.15.7 \pm 2.7\right)$. Male flat jockeys had significantly smaller value FMI and BF\% compared to female flat jockeys $(24.4 \pm 3.7)$. In contrast, male flat jockeys had significantly higher values of LMI than that of the female flat jockeys $\left(14.7 \pm 0.9 \mathrm{~kg} / \mathrm{m}^{2}\right)$.

\section{Discussion}

The results from this study give us a picture of current bone health and body composition in a large group of newly
Table 2 Bone mass information according to gender and type of racing

\begin{tabular}{|c|c|c|c|c|c|}
\hline & $\begin{array}{l}\text { Male } \\
\text { Flat }\end{array}$ & Jump & $\begin{array}{l}\text { Female } \\
\text { Flat }\end{array}$ & $\begin{array}{l}\text { Flat-male vs. } \\
\text { flat-female } \\
p \text { value }\end{array}$ & $\begin{array}{l}\text { Flat-male vs. } \\
\text { jumps-male } \\
p \text { value }\end{array}$ \\
\hline Spine BMC (g) & $51.85 \pm 7.27$ & $65.26 \pm 9.04$ & $54.71 \pm 6.23$ & $<0.05$ & $<0.001$ \\
\hline $\begin{array}{l}\text { Spine BMD } \\
\left(\mathrm{g} / \mathrm{cm}^{2}\right)\end{array}$ & $0.876 \pm 0.091$ & $0.969 \pm 0.087$ & $0.987 \pm 0.083$ & $<0.001$ & $<0.001$ \\
\hline $\begin{array}{l}\text { Spine BMAD } \\
\left(\mathrm{g} / \mathrm{cm}^{3}\right)\end{array}$ & $0.114 \pm 0.011$ & $0.118 \pm 0.011$ & $0.132 \pm 0.013$ & $<0.001$ & $<0.05$ \\
\hline $\begin{array}{c}\text { Z-score } \leq-1.0, \\
n(\%)\end{array}$ & $60(76.0)$ & $36(52.2)$ & $6(16.2)$ & $<0.001$ & $<0.001$ \\
\hline $\begin{array}{c}\text { Z-score } \leq-2.0, \\
n(\%)\end{array}$ & $23(29.1)$ & $9(13.0)$ & $1(2.7)$ & $<0.001$ & 0.01 \\
\hline FN BMC (g) & $4.43 \pm 0.38$ & $5.26 \pm 0.69$ & $4.06 \pm 0.48$ & $<0.001$ & $<0.001$ \\
\hline $\begin{array}{r}\text { FN BMD } \\
\left(\mathrm{g} / \mathrm{cm}^{2}\right)\end{array}$ & $0.831 \pm 0.070$ & $0.935 \pm 0.093$ & $0.840 \pm 0.077$ & 0.534 & $<0.001$ \\
\hline $\begin{array}{c}\text { FN BMAD } \\
\left(\mathrm{g} / \mathrm{cm}^{3}\right)\end{array}$ & $0.155 \pm 0.113$ & $0.168 \pm 0.023$ & $0.176 \pm 0.023$ & $<0.001$ & $<0.001$ \\
\hline $\begin{array}{c}\text { Z-score } \leq-1.0, \\
n(\%)\end{array}$ & $27(34.2)$ & $6(8.7)$ & $3(8.1)$ & 0.002 & $<0.001$ \\
\hline $\begin{array}{c}\text { Z-score } \leq-2.0, \\
n(\%)\end{array}$ & $1(1.3)$ & - & - & - & - \\
\hline $\begin{array}{l}\text { Total hip BMC } \\
\text { (g) }\end{array}$ & $35.01 \pm 3.84$ & $43.18 \pm 6.25$ & $30.22 \pm 4.03$ & $<0.001$ & $<0.001$ \\
\hline $\begin{array}{l}\text { Total hip BMD } \\
\left(\mathrm{g} / \mathrm{cm}^{2}\right)\end{array}$ & $0.924 \pm 0.084$ & $1.017 \pm 0.100$ & $0.959 \pm 0.075$ & 0.04 & $<0.001$ \\
\hline $\begin{array}{l}\text { Z-score } \leq-1.0 \\
n(\%)\end{array}$ & $33(41.8)$ & $7(10.1)$ & $1(2.7)$ & $<0.001$ & $<0.001$ \\
\hline $\begin{array}{c}\text { Z-score } \leq-2.0, \\
n(\%)\end{array}$ & - & - & - & - & - \\
\hline
\end{tabular}

Values are mean \pm SD except where noted. Six jockeys did not have data available for BMD Z-score at the spine and five jockeys did not have available BMD Z-score at neither FN or at total hip. Seven jockeys did not have data available for BMC at all skeletal sites

$B M C$ bone mineral content, $B M D$ bone mineral density, $B M A D$ bone mineral apparent density, $F N$ femoral neck 
Fig. 1 Box plots of a BMI (kg/ $\left.\mathrm{m}^{2}\right)$, b LMI $\left(\mathrm{kg} / \mathrm{m}^{2}\right)$, c FMI and $\mathbf{d}$ $\mathrm{BF}(\%)$ according to gender and type of racing. $B M I$ body mass index, $L M I$ lean mass index, $F M I$ fat mass index, $B F$ body fat
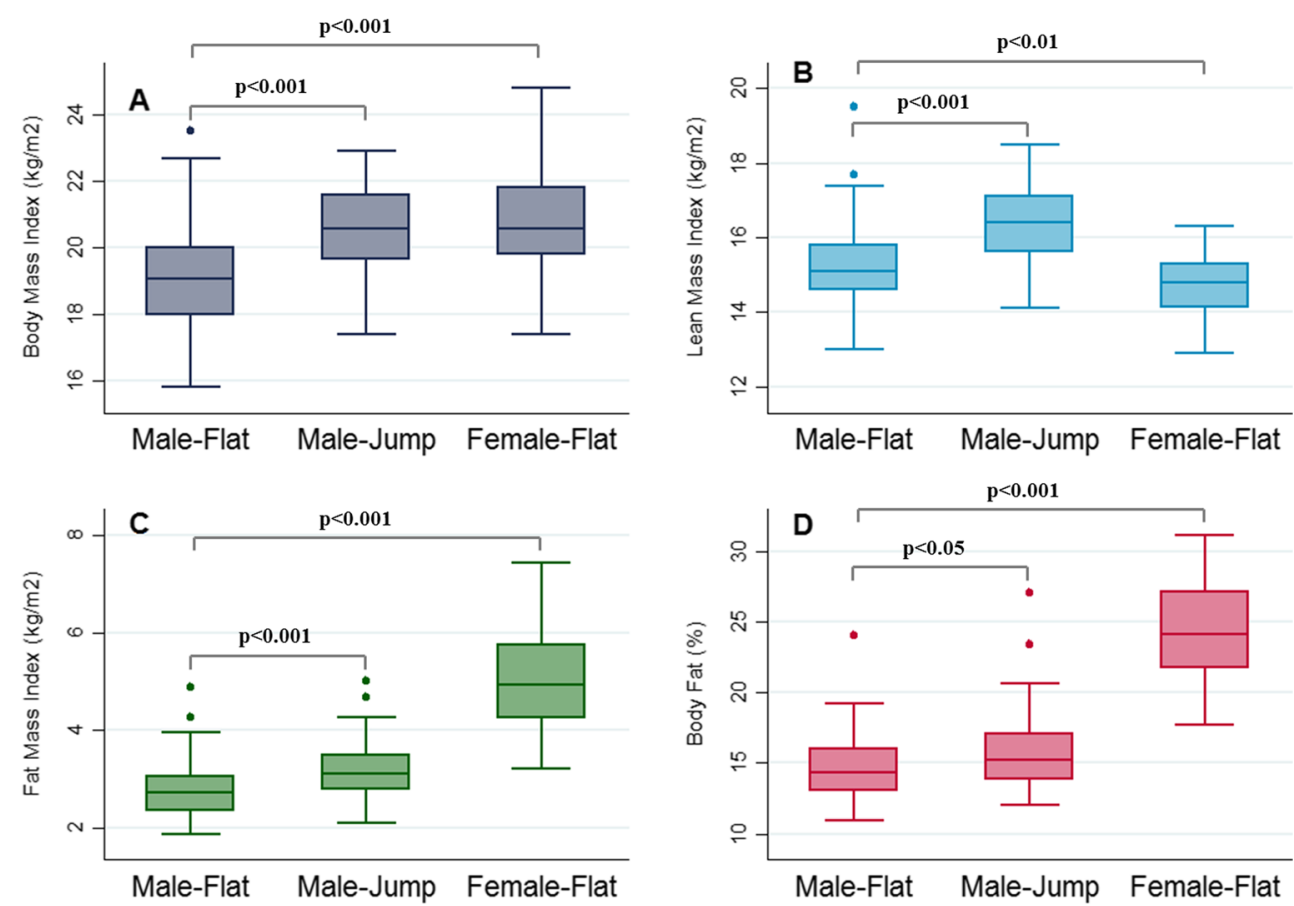

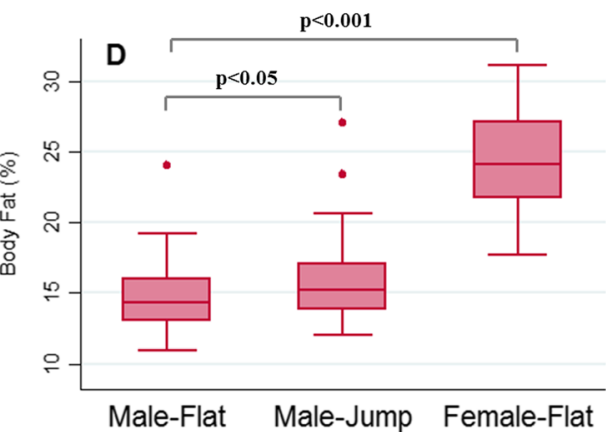

licenced professional jockeys. To date, in the published literature, studies of bone health and body composition in professional jockeys have been relatively small, typically between 10 and 20, predominantly male jockeys. Male jockeys have been shown to have lower bone density than the normal population $[6-9,11]$, lower body fat $[2,6,8,9,11]$ and lower lean mass $[6,11]$. One of the few studies to include female jockeys reported normal bone density [11] whilst another study showed two female jockeys $(n=5)$ were osteopenic, [8].

Our study is a large and generalisable representation of newly licenced jockeys confirming previous findings of low BMD in male jockeys whilst extending our understanding of bone health in female jockeys and body composition values in all jockeys. We found that $76 \%$ of male, flat jockeys have a low spine BMD (less than one SD below the average in the age-sex-reference) and 29\% had a very low BMD (less than two SD below the average age-sex-reference [20]), as opposed to the expected 16 and $2.5 \%$, respectively. However, these observations were not limited to the flat-male jockeys with $52 \%$ of jump jockeys also having a low BMD at the spine. Female jockeys had normal BMD at all sites. We observed that male flat jockeys had a significantly lower BMD in their spines than female flat jockeys. This observed difference is opposite to the general population where women have a lower spinal BMD than men. This reversal has been observed before in a small $(n=16)$ voluntary group of male and female flat jockeys, [11]. This larger generalisable cohort confirms these findings.

The factors affecting bone health in jockeys have been the subject of several studies. Intrinsic factors are centred around poor nutrition with a reduced calorie intake leading to a state of energy deficiency [2, 3, 7-9, 11, 24]. The resulting low energy availability is thought to affect the hormonal profile [7] and negatively affect metabolic processes including the rate of bone protein synthesis and bone mineralisation, [3, 9, 11]. Reduced calcium intake and low vitamin D may also contribute although short-term supplementation has not shown to affect bone material properties in young jockeys [25-27]. Extrinsic factors may impact bone health such as smoking or the amount of weight-bearing exercise performed. Dolan et al. found that $38 \%$ of jockeys in their study smoked and over half admitted to using it as a form of weight control [2]. The efforts of flat jockeys to maintain a very low minimum weight in order to race is leading to poor bone health through a combination of the above factors. Our observed differences in BMD between flat and jump jockeys is likely the result of the higher minimum race-riding weight of 10 stone $(63.5 \mathrm{~kg})$ for jump jockeys, compared to 8 stone $(50.8 \mathrm{~kg})$ for flat jockeys. The observed differences between male and female jockeys can also be explained by their shorter stature allowing them to make weight without resorting to such severe or persistent weight loss strategies [11]. Poor bone health in male jockeys is happening at a time when these young men are reaching peak bone mass. A large longitudinal study has demonstrated differing ages for peak bone mass (PBM) between sexes and at different sites [28]. Male total hip and femoral neck PBM was achieved between 19 and 22 years of age and 17-19 years of age respectively and male lumbar spine PBM occurred between 19 and 33 years.

Body composition and demographic results confirm previous findings of lighter, smaller flat jockeys compared to jump jockeys. It also confirms the finding of lower LM in jockeys. 
The average BMI in all three groups of jockeys was predominantly in the lower half of normal range (normal BMI 18.5$25)$, running into underweight particularly in the male flat jockeys. BF\% was only slightly lower in all jockey groups than the general population. The BF\% of male flat, male jump and female flat jockeys were $14.6 \pm 2.25,15.67 \pm 2.68$ and $24.35 \pm 3.68$, respectively, which is lower than that of 18 to 34-year-old males and females from the general population (17.9 \pm 4.7 and $28.7 \pm 6.4$, respectively) [29]. The BF\% of flat, male jockeys in this larger cohort is at odds with previous smaller studies of male, flat jockeys where $\mathrm{BF} \%$ values were found to be much lower [2, 6, 9, 11]. FMI (accounting for height) in male flat jockeys in our study was $2.7 \pm 0.5 \mathrm{~kg} /$ $\mathrm{m}^{2}$. A previous small study in male, flat jockeys reported FMI as significantly lower $(1.65 \pm 0.62)[6]$. This discrepancy in FM raises the question of recruitment bias in these small studies where volunteers may already be interested in their body composition and therefore actively maintaining lower BF than their peers who did not volunteer. One study of flat, male professional jockeys $(n=19)$ found BF\% of $13 \pm 3.0$ which is nearer the findings of our larger cohort, but this cohort of jockeys was considerably older ( $27 \pm 5$ years) than our newly licenced group. It is likely they are riding at higher weights as they will no longer be carrying a claim. There are a number of studies looking at BF \% (means) in other weight-restricted and lightweight sports: male lightweight rowers $8.5 \%, n=120$, mean age 21 years [30]; wrestling $8.3 \%, n=35$, mean age 24.3 years [30]; female sub-elite cyclists $16 \%, n=76$, mean age 23.8 years [31]; male competitive club cyclists $9.9 \%$, $n=14$, mean age 28.1 years [32] and male boxers $9.76 \%$, $n=14$, mean age 21 years [6]. BF\% in these studies is significantly lower than for our jockey cohort.

Population based studies of LMI in men have reported higher values than in our male jockey population. NHANES data of white male age range 20-25 $(n=235)$ had an average LMI of 19.0 and white, 20 to 25 -year-old females $(n=323)$ had an average LMI of 16.0, [21]. The Hertfordshire cohort study reported LMI in men of $17.82 \pm 1.44$ and women of $15.06 \pm 1.55$, [33]. A small study of jockeys used physically active male, age- and BMI-matched controls and the controls had LMI of $18.2 \pm 1.51$ [7]. In the same study, LMI is reported in professional jockeys as $18.33 \pm 1.46$. Another small study of flat jockeys as $18.19 \pm 1.3(n=14)$ and in jump jockeys as $18.125 \pm 1.23(n=16)$. Several studies look at LM $(\mathrm{kg})$, but direct comparison of LM without correcting for height difference between sports makes this difficult to interpret. One small study found the LMI in boxers $(n=14)$ to be $18.25 \pm 1.23$ [6]. The male, flat and jump jockeys had significantly lower LMI $\left(15.3 \pm 1.1\right.$ and $16.4 \pm 1.1 \mathrm{~kg} / \mathrm{m}^{2}$, respectively) than all the groups studied above. As we do not know the maturation status of our jockeys, there may have been a number of the youngest jockeys who had not yet fully physically matured. However, using an age-specific stratified analysis according to time of expected peak LMI ( $<19$ vs. $\geq 19$ years) [28], both groups still exhibited a low LMI which suggests there may be other factors involved (Table A.2.2).

These observed differences in body composition may be related to the weight loss practices in the jockey population. Cyclical daily efforts to make weight for each race-ride may be having a detrimental effect on metabolism with loss of lean mass instead of fat mass. In addition, some jockeys may be intentionally avoiding types of exercise that they believe could increase muscle mass as part of their weight control strategy. Time pressure from extensive travelling between races also reduces the chance of these young jockeys doing any dedicated fitness training.

\section{Strengths and limitations}

The strengths of this study are that it is the largest crosssectional study of male and female jockey BMD and body composition. With almost full recruitment, it is highly generalisable. All the jockeys were newly licenced, increasing the homogeneity of the cohort.

The limitations of this study are that the DEXA scans were performed on three different scanners (all Hologic scanners). A phantom spine study was performed to observe any differences between the two Hologic Discovery scanners. The differences in BMD were clinically insignificant (Appendix A.1). The Hologic Explorer machine had been dismantled so we were unable to include it in comparison study. However, we performed a sensitivity analysis excluding jockeys measured by the Explorer scan and found no significant impact on the results and interpretation of this study (Table A.2.1). The other important limitation of this study was the nonavailability of any indicator of maturation; therefore, we could not determine whether there was a high proportion of late maturers in this population. We conducted an age-specific stratified analysis according to time of expected peak BMD (younger $<21$ year, and older 21 years or older). The percentage of BMD Z-score $<-2.0$ in both age groups was significantly higher than expected for their chronological age (Table A.2.3).

\section{Conclusion}

This study in a large, representative group of professional, entry-level jockeys has confirmed that $29 \%$ of newly licenced male, flat jockeys have a very low BMD (Z-score $\leq-2)$ in their spines. This is occurring at an age when these young jockeys are reaching their peak bone mass, which strongly influences future bone health and fracture risk. What is currently less clear is how less-than-optimal bone health influences immediate fracture risk in these young jockeys. The male, flat jockeys have a significantly lower BMD at the spine 
than female flat jockeys, which is the reverse of the normal population. This study also identified that flat jockeys appear to have a proportional lower LM than would be expected in both the normal population and other low-weight sports. The study cohort was young and so maturation may contribute to these findings. This study provides robust evidence of poor male jockey bone health to support previous findings as well as body composition data on a large jockey cohort. We would recommend further research establishing the relationship between poor bone health in newly licenced jockeys and subsequent injury in this population, as well as the relationship between body composition and rates of falls and injury.

Acknowledgements This research was supported by the British Horseracing Authority, the Professional Jockeys Association (PJA) and the Injured Jockey Fund (IJF).

\section{Compliance with ethical standards}

Funding This study was funded by the Racing Foundation (grant number HFR00920) and the British Association of Sport and Exercise Medicine (grant number HFR00840).

Conflict of interest MTSS, AT, KK, CB, SE: None. JN, ALM and KJ received a grant from the Racing Foundation. KAJ received a grant from the British Association of Sport and Exercise Medicine. MKJ: In the last 5 years received honoraria, travel and/or subsistence expenses from Amgen, Eli Lilly, Medtronic, Servier, Shire, Internis, Consilient Health, Stirling Anglia Pharmaceuticals, Mereo Biopharma and Optasia. CC received grants from NIHR HS\&DR during the conduct of the study and personal fees from Servier, Amgen, Eli Lilly, Merck, Medtronic and Novartis, outside of the submitted work. NA received personal fees from Flexion, Bioventus, Merck, Q-Med, Roche, Smith \& Nephew, Bioiberica and Freshfields, outside of the submitted work.

Open Access This article is distributed under the terms of the Creative Commons Attribution 4.0 International License (http:// creativecommons.org/licenses/by/4.0/), which permits unrestricted use, distribution, and reproduction in any medium, provided you give appropriate credit to the original author(s) and the source, provide a link to the Creative Commons license, and indicate if changes were made.

\section{References}

1. Mottershead L (2016) Racing Post article discussing the health risks of 'flipping'. [cited 2016 12/5/16]; Available from: http://www. racingpost.com/news/horse-racing/jockeys-putting-themselves-ata-huge-health-risk-every-day/2029793/ - newsArchiveTabs= last7DaysNews.

2. Dolan E et al (2011) Nutritional, lifestyle, and weight control practices of professional jockeys. J Sports Sci 29(8):791-799

3. Wilson $\mathrm{G}$ et al (2014) Weight-making strategies in professional jockeys: implications for physical and mental health and well-being. Sports Med 44(6):785-796

4. Dolan E et al (2013) The impact of making weight on physiological and cognitive processes in elite jockeys. Int J Sport Nutr Exerc Metab 23(4):399-408

5. Weaver CM et al (2016) The National Osteoporosis Foundation's position statement on peak bone mass development and lifestyle factors: a systematic review and implementation recommendations. Osteoporos Int 27(4):1281-1386

6. Dolan E et al (2012) Weight regulation and bone mass: a comparison between professional jockeys, elite amateur boxers, and age, gender and BMI matched controls. J Bone Miner Metab 30(2):164-170

7. Dolan E et al (2012) An altered hormonal profile and elevated rate of bone loss are associated with low bone mass in professional horse-racing jockeys. J Bone Miner Metab 30(5):534-542

8. Leydon MA, Wall C (2002) New Zealand jockeys' dietary habits and their potential impact on health. Int J Sport Nutr 12(2):220-237

9. Warrington $\mathrm{G}$ et al (2009) Chronic weight control impacts on physiological function and bone health in elite jockeys. J Sports Sci 27(6):543-550

10. Wilson $\mathrm{G}$ et al (2013) Markers of bone health, renal function, liver function, anthropometry and perception of mood: a comparison between flat and national hunt jockeys. Int J Sports Med 34(5): 453-459

11. Wilson $\mathrm{G}$ et al (2015) Elite male flat jockeys display lower bone density and lower resting metabolic rate than their female counterparts: implications for athlete welfare. Appl Physiol Nutr Metab 40(12):1318-1320

12. Mackey DC et al (2007) High-trauma fractures and low bone mineral density in older women and men. JAMA 298(20):2381-2388

13. Rueda MA, Halley WL, Gilchrist MD (2010) Fall and injury incidence rates of jockeys while racing in Ireland, France and Britain. Injury 41(5):533-539

14. Turner M, McCrory P, Halley W (2002) Injuries in professional horse racing in Great Britain and the Republic of Ireland during 1992-2000. Br J Sports Med 36(6):403-409

15. Cui LH et al (2007) Relative contribution of body composition to bone mineral density at different sites in men and women of South Korea. J Bone Miner Metab 25(3):165-171

16. Lekamwasam S et al (2009) Association between bone mineral density, lean mass, and fat mass among healthy middle-aged premenopausal women: a cross-sectional study in southern Sri Lanka. J Bone Miner Metab 27(1):83-88

17. Liu YH et al (2013) Association of weight-adjusted body fat and fat distribution with bone mineral density in middle-aged Chinese adults: a cross-sectional study. PLoS One 8(5):e63339

18. Wilson G, Hawken MB, Poole I, Sparks A, Bennett S, Drust B, Morton J, Close GL (2013) Rapid weight-loss impairs simulated riding performance and strength in jockeys: implications for making weight. J Sports Sci 32(4):383-391

19. Report of a WHO Study Group (1994) Assessment of fracture risk and its application to screening for postmenopausal osteoporosis. World Health Organ Tech Rep Ser 843:1-129

20. Writing Group for the ISCD Position Development (2004) Conference, Diagnosis of osteoporosis in men, pre-menopausal women and children, in J Clin Densitom. p. 17-26.

21. Kelly TL, Wilson KE, Heymsfield SB (2009) Dual energy X-ray absorptiometry body composition reference values from NHANES. PLoS One 4(9):e7038

22. Katzman DK et al (1991) Clinical and anthropometric correlates of bone mineral acquisition in healthy adolescent girls. J Clin Endocrinol Metab 73(6):1332-1339

23. Carter DR, Bouxsein ML, Marcus R (1992) New approaches for interpreting projected bone densitometry data. J Bone Miner Res 7(2):137-145

24. O'Reilly J, Cheng HL, Poon ET (2017) New insights in professional horse racing; "in-race" heart rate data, elevated fracture risk, hydration, nutritional and lifestyle analysis of elite professional jockeys. J Sports Sci 35(5):441-448

25. Waldron-Lynch F et al (2010) High bone turnover in Irish professional jockeys. Osteoporos Int 21(3):521-525

26. Silk LN, et al. (2016) The effect of calcium and vitamin D supplementation on bone health of male Jockeys. J Sci Med Sport 
27. Silk LN et al (2015) Tibial bone responses to 6-month calcium and vitamin D supplementation in young male jockeys: a randomised controlled trial. Bone 81:554-561

28. Berger $\mathrm{C}$ et al (2010) Peak bone mass from longitudinal data: implications for the prevalence, pathophysiology, and diagnosis of osteoporosis. J Bone Miner Res 25(9):1948-1957

29. Schutz Y (2002) Fat-free mass index and fat mass index percentiles in Caucasians aged 18-98y. Int J Obes 26:953-960

30. Fleck S (1983) Body composition elite American athletes. Am J Sports Med 11(6):398-403
31. Haakonssen EC, et al. (2015) Body composition in female road and track endurance cyclists: normative values and typical changes in female road and track endurance cyclists. European Journal of Sport Science

32. Stewart AD, Hannan $\mathrm{J}$ (2000) Total and regional bone density in male runners, cyclists, and controls. Med Sci Sports Exerc 32(8): 1373-1377

33. Edwards MH et al (2013) Muscle size, strength, and physical performance and their associations with bone structure in the Hertfordshire Cohort Study. J Bone Miner Res 28(11):2295-2304 